\title{
STRATEGIES OF MAINTAINING PROFICIENCY BY TEACHERS OF ENGLISH IN INDONESIA
}

\author{
Junaidi Mistar dan Alfan Zuhairini
}

\author{
Email: alfan_zuhairini@yahoo.com \\ Universitas Islam (Unisma) Malang \\ Alamat Korepondensi: Jalan MT. Haryono 193 Malang 65144 Jawa Timur
}

\begin{abstract}
The objectives of the present study are four-fold: (1) to identify the types of strategies to maintain proficiency used by teachers of English in Indonesia, (2) to know the intensity of use of the obtained strategy types, (3) to measure the inter-correlation in the use of the obtained strategy types, and (4) to investigate the effect of proficiency level on the use of maintaining strategies. The subjects were 93 teachers applying for S2 degree in 2010/2011 at the postgraduate program of the Islamic University of Malang. They were given two sets of instrument, a Likert-scale questionnaire of English proficiency maintaining strategies and a TOEFL test. Then, a factor analysis identified nine strategy categories, including language focusing, metacognitive and affective developing, reading and writing activating, language resource utilizing, cognitive processing, culture learning, social communicating, text analyzing, and radio listening strategies. These strategy types explained $63.84 \%$ of variances of maintaining strategies and they were used at high level of intensity. Moreover, the use of the nine strategy types were found to be inter-correlated with one another. Finally, no significant effect of proficiency level on strategy use was found, indicating that teachers with different level of proficiency reported using the same strategies of maintaining their proficiency.
\end{abstract}

\section{Keywords}

Maintaining Strategies, Strategy Categories, Proficiency, Correlation

\section{Introduction}

In the discussion of the topic on developing proficiency in a foreign language, two aspects are worth exploring: learning strategies and maintaining strategies. While the first concept refers to actions the learners take during their foreign language learning activities, the latter concept refers to the actions they take after the formal learning activities have ceased in order to maintain the attained foreign language proficiency.

Research in the area of learning strategies was initiated by investigations of the characteristics of good language learners (Stern, 1975; Rubin, 1975; Rubin \& Thomson 1983). Rubin and Thomson (1982), for example, found that 'good' language learners tend to exhibit some characteristics such as 1) finding their own way, 2) organizing information about language, 3) making their own opportunities and strategies for getting practice in using the language inside and outside the classroom.
Further research in this area deals with identification of strategies that good language learners use. In Asian contexts, Nunan (1991) investigated 44 good language learners and EFL teachers who experienced EFL in Hong Kong, Thailand, Indonesia, the Philippines, Singapore and Malaysia. He identified the strategies that good language learners use, including 1) making communication with native speakers outside class, 2) reading various kinds of printed materials in English, 3) listening to native speakers through radio and TV, listening to the songs and singing the songs, 4) watching TV and cinema, 5) visiting English speaking countries for communicating with native speakers, 6) practicing through conversation with proficient speakers in English and using the media, 7) creating a social interaction (exposure and practice the language) at home and with friends, and 8) practicing language outside the classroom.

Research in the area of learning strategies is even more popular when Oxford (1990) developed a Strategy Inventory for Language Learning (SILL) based on her classification of learning strategies. 
In general, she classified learning into two broad categories: direct strategies and indirect strategies. The direct strategies, those that deal with the use of the target language, consist of memory, cognitive, and compensation strategies. Meanwhile, the indirect strategies, those that do not directly involve the use of the target language but support the language learning activities, consist of metacognitive, affective, and social strategies. Fifty items of strategies were developed out of these six types of strategies.

Concerning with the role of learning strategies, despite some findings that indicate no correlation between learning strategies and English proficiency (Politzer \& McGroarty, 1985; Oxford and Ehrman, 1995), the majority of research reported that they are significant factors of language learning success (Park, 1997; Mistar, 2001; Mistar, 2006). This fact implies that success in foreign language learning is to a large extend affected by the learners' learning strategies.

Upon the termination of the formal learning period, learners face new tasks of maintaining their language proficiency. As a matter of fact, maintaining foreign language proficiency in unfavorable circumstances, like English in Indonesia, where most people in the society do not use English and where English native speakers are hardly available for learners to practice, is a hard job. Otherwise, their English proficiency will gradually decrease. This phenomenon is called language attrition. Thus, the discussion of language maintenance is very closely related with that of language attrition.

At least two factors may be predicted to influence language maintenance: (1) personal factors, and (2) environment. Within the personal factor category, a number of factors may be listed. First is the basic language ability as it affects how language proficiency is maintained (Bahrick, 1984; Clark and Jorden, 1984; Weltens, Van Els and Schils, 1989), particularly in terms of grammatical complexity, lexical complexity, and lexical productivity (Tomiyama, 2008). The second personal factor is the age at which acquisition takes place. The idea is that foreign language maintenance hardly occurs among very young learners. In other words, younger learners are more vulnerable to attrition than older learners are (Cohen, 1989). Futhermore, Berman and Olstain (1989) found that the greatest loss, in terms of quantity and quality alike, was shown by the youngest children, from age five through age eight. In sum, the younger a child is, the more rapid the pace of language attrition will be. Next is attitude and motivation, with an idea that positive attitudes support motivation, which in turn promotes a long-term retention of learned material. Nagasawa (1999) finds that motivation and attitude are important factors both during the period of learning and during the period of reduced input and use. And the last is the proficiency level that a learner achieves in his learning or acquisition period. Tomiyama (2000) found that the attained proficiency level of English when a subject returns to Japan and the acquired literacy skill seemed to have contributed to the child's prolonged retention of English ability in EFL setting. Earlier, Tomiyama (1998) claimed that an attained high proficiency level is an important factor in the maintenance of a second language. Research findings that the initial achievement of advanced high was a strong predictor for retention of speaking skills (Nagasawa, 1998) and that high competence at study onset was the most predictive factor of L2 retention (Kurashige, 1999) support the claim.

Environmental support, the second factor, is also crucial for language maintenance. A linguistic situation in which people can practice using the language for daily communication can be an effective way to maintain language proficiency (Oxford, 1988). Sider (2003) found that besides personal motivation, exposure from the genuine "environment" from which a speaker acquired a certain language is also very crucial for language retention. Furthermore, without regular and frequent practices to use the language for routine communication, the logical consequences in the form of language loss are unavoidable. Thus, the more practice apportunities ones who wish to maintain their skills have, the greater the likelihood they should be successfull in doing so (Raffaldini, 1989).

In spite of the availability of much literature on factors affecting language maintenance, literature on how language maintenance can be maximized remains very little. Oxford (1988) state that when former learners no longer have a teacher to structure and present language material or to provide opportunities for practice, learning strategies can go a long way to providing them with the kind of support that is often necessary for maintaining language skills. She further provides some kinds of learning strategies which can be adopted for alternative ways to maintain English proficiency after learners graduated or when there is no more teacher in the language classroom.

Thus, some strategies should be applied to maintain the acquired language proficiency. If maintaining strategies are not put into action, the so-called attrition process of language will 
logically occur. Thus, to help them able to use maintaining strategies, the strategies should be identified first. It is for this purpose that the present research is carried out. In addition, differences in the use of maintaining strategies among speakers with different level of proficiency are also investigated. Thus, the research problems are formulated as follows: 1) What types of strategies do teachers of English in Indonesia use to maintain their English proficiency?, 2) How is the profile of the use of the English proficiency maintaining strategies?, 3) Does the use of English proficiency maintaining strategies correlate one another? 4) Do teachers of English with different proficiency levels use maintaining strategies at different frequencies?

\section{Method}

\section{Subjects of the Study}

The subjects of the present study were teachers of English who applied for a magister (S2) program at the postgraduate program of the Islamic University of Malang in 2010/2011. Actually, there were 114 teachers applying for the program, but only 93 teachers, 40 male and 53 females, were used as the subjects of the study as they perceived themselves as being able to maintain and even improve their English proficiency upon graduating from their S1 study. Meanwhile, 24 teachers thought that their English proficiency was decreasing since their S1 graduation.

Further characteristics of the subjects are as follows. In terms of residence, they come from 24 regencies with significant numbers are from Malang $(n=13)$, Pasuruan $(n=8)$, Kediri $(n=7)$, Madiun $(n=6)$, Tulungagung and Bojonegoro $(n=5$ each), and Bangkalan, Blitar, Jember, and Lumajang $(n=2)$ each. The rest are from 14 regencies with only 1 teacher from each. Moreover, in terms of age, the youngest was 22 years old $(n=2)$ and the oldest was $65(n=1)$ with a majority being below 30 years old $(n=48)$. Finally, in terms of their teaching position, 7 teachers are teaching at elementary school level, 32 at junior high school level, 30 at senior high school level, 11 at tertiary education level, and 13 not known.

\section{Research Instrument}

Two research instruments were used in the present study: (1) an English maintaining strategy questionnaire, and (2) a TOEFL test. Some items in the questionnaire were selected from items of learning strategies as proposed by
Oxford (1990) and some others were developed on the basis on classification of learning strategies by O'Malley dan Chamot (1990). The two approaches to questionnaire development resulted in 75 items of language maintaining strategies. The questionnaire was in a structured form of Likert scale type and the subjects were asked to respond to each item in terms of how often they used a given language maintaining strategy. Five alternatives of frequency of use were provided with 1 indicating never, 2 seldom, 3 sometimes, 4 often, and 5 always.

Meanwhile, the TOEFL test was taken from Longman Complete Course for the TOEFL Test (Phillips, 2001). Like other TOEFL test, this test consists of three sections: Section 1, Listening Comprehension (50 items), Section 2, Structure and Written Expression (40 items), and Section 3, Reading Comprehension (50 items). The whole test was completed in about 2 hours.

Prior to the use of the questionnaire for data collection, it was tried-out to 42 second semester students of S2 program of the Islamic University of Malang to check its validity and reliability. In this case an analysis of the construct validity was the main focus and it was done by correlating the score of each individual item with the total score. Negative correlations and insignificant positive correlations were interpreted that the items did not provide significant contribution to the measurement of the intended construct so that they had to be eliminated. The results of the analysis, however, showed that all items had significant positive correlation with the total questionnaire. Thus, those 75 items remained to be used in the study. Moreover, an analysis of the reliability index using Cronbach Alpha found a reliability estimate .972 , suggesting that the instrument would produce highly reliable data.

Meanwhile, the quality of the TOEFL test was assumed to be good in terms of both validity and reliability. Such an assumption is based on the fact that the test resembles the real paper-based TOEFL test that it contains 3 sections is administered in 115 minutes. Moreover, the fact that scores from this TOEFL test have been used for academic purposes in a number of universities in Malang, Indonesia, supports an assumption of its good reliability.

\section{Procedure of Data Analysis}

As the main purpose of the present study is to classify English maintaining strategies into a number of categories, a factor analysis was performed. Thus, the underlying factors of the 75 strategy items were firstly discerned by using the 
Principal Component Analysis (PCA). The component matrix was rotated using the Varimax with Keiser Normalisation Method and the resulting factors were then treated as posteriori strategy categories. Thus, prior to the factor analysis, the factorability of the data was inspected by examining two out of three criteria. They were that (1) the Bartlett's test of sphericity should be significant, and (2) the Kaiser-MeyerOklin (KMO) value should be at least .6 (Pallant 2001). The identified factors were then named to represent a strategy category.

Next, the average score of the use of each strategy category was analyzed to find the patterns of the intensity of use. The intensity of use is interpreted as being high if the mean score of use is between 3.45 and 5.00 , medium if it is between 2.45 and 3.44, and low if it is between 1.00 and 2.44. Then, correlation analyses were performed to investigate the inter-relationship of the use of each strategy category. Finally, the use of the identified strategy categories was compared among subjects with different proficiency level. In this case, the subjects were classified into 3 groups: lower, moderate, and upper based on the mean and standard deviation of their TOEFL scores.

\section{Findings and Discussion}

\section{Findings}

The results are presented in the order of the questions addressed in this study. As mentioned earlier, four questions were addressed in this study and the answers to each of them are described below.

Question One: What types of strategies do teachers of English in Indonesia use to maintain their English proficiency?

Prior to factor analysis to find out the types of strategies the teachers executed to maintain their English proficiency, the factorability of the data was inspected. The inspection revealed that the Kaiser-Meyer-Oklin (KMO) measure of sampling adequacy resulted in a value .684 and the Bartlett's test of sphericity found a Chi-Square value $6271.765(p<.000)$. These two forms of evidence guarantee a good factor analysis using the Principal Component Analysis (PCA).

The analysis revealed the presence of nine components or factors with an initial eigen-value greater than 1.5 explaining a cumulative variance of $63.84 \%$. Out of the nine factors, six factors explain variances more than $3 \%$ each and the other three factors explain less than $3 \%$ each. Of the six factors in the first category, the most dominant one accounted for $34.47 \%$ of the total variance of maintaining strategies. This factor obtained high loadings (more than .3) from fifteen strategy items which chiefly deal with focusing on form more than on meaning when using English both in spoken and written situation. These include strategies of trying to identify text structure when reading, practicing the learned grammar in speaking and writing, analyzing the correctness of the language when speaking and writing, paying attention to the language of other speakers when in a conversation, and learning from grammatical mistakes. Thus, this factor was described as a factor of language focusing strategies. Factor 2, moreover, accounted for $6.41 \%$ of the variance. Fourteen strategy items provided high loadings to this factor and they mainly deal with metacognitive and affective activities, such as making schedules of activities to use English, following schedules consistently, monitoring effectiveness of scheduled activities, assessing effectiveness of strategies, assessing English performance, and self-encouraging to maintain English. Thus, this factor was described as a factor of metacognitive and affective developing strategies. Factor 3, which explained $5.33 \%$ of the variance in learning strategies, obtained high loadings from thirteen strategy items. The strategies mainly deal with reading and writing activities to maintain English, such as reading newspapers, periodicals, novels, popular scientific materials, and textbooks in English and writing messages and notes in English. Thus, this factor is named reading and writing activating strategies. Factor 4, explaining $3.69 \%$ of the learning strategy variance, is described as language resource utilizing strategies as this factor obtain high loadings from nine strategy items that deal with the use of English resources for maintaining their English proficiency. Such strategies as using English songs, internet, and commands in computer menu, watching television programs and news, as well as listening to English voices in tape recorder, VCD, and DVD provide high loadings to this factor. Factor 5 which explained $3.56 \%$ of the variance in learning strategies, obtained high loadings from seven strategy items. The strategies mainly corcern with cognitive processing activities, such as utilizing glossaries when reading, finding synonyms of English words in the first language (bahasa Indonesia), fiding similarities and differences of grammatical patterns of English and Bahasa Indonesia, repeating word use, and imitataing native speakers. Thus, this startegy category is labelled as cognitive processing strategies. And, factor 6 explaining $3.08 \%$ of the 
variance obtains high loadings from five strategy items that mainly concern with strategies to maintain English proficiency through learning the culture of the native speakers of English, such as learning the history of Englishmen, learning the culture, and reading novels, poems, and short stories. Thus, this factor is described as culture learning strategies.

The other three factors explain less than $3 \%$ of the variance each. Factor 7, for example, explain $2.55 \%$ of maintaining strategy variance and it obtains high loadings from five strategy items that deal with the teachers' actions in using English for social communicating among them, such as having special partners to use English, creating situations/opportunities to use English, and communicating via email/facebook in English. Thus, this factor is named social communication strategies. Factor 8, moreover, explains $2.49 \%$ of strategy variance and it gets high loadings from four strategy items, including taking notes of important points when reading and using transition markers to understand texts. Thus, this factor is named text analyzing strategies. Finally, the last strategy category, factor 9 explaining $2.24 \%$ of strategy variance, gets high loadings from three strategy items that mainly deal with activities to listen to radio programs such as American VOA, British BBC, and Australian ABC. Thus, this factor is called radio listening strategies. The complete presentation of the strategies that provide high loadings to each factor is presented in Appendix 1.

Question 2: How is the profile of the use of the English proficiency maintaining strategies?

The data of the respondents' intensity of use of maintaining strategies as analyzed in terms of each strategy categories as well as overall strategies are presented in Table 1 . The table shows that the overall use of maintaining strategies by Indonesian teachers of English was at the high level $(M=3.48$, s.d.=.589). As far as the strategy categories were concerned, the most frequently used strategy category was language focusing strategy category ( $\mathrm{M}=4.04$, s.d.=.671) and the least frequently used one was radio listening strategy $(\mathrm{M}=2.09$, s.d.=.871). A Further analysis found that five categories were used at the high level, three categories at the moderate level, and one category at the low level. The strategies found to be used at the high level were language focusing strategies, cognitive processing strategies, text analyzing strategies, language resource utilizing strategies, and social communicating strategies. Moreover, the strategies used at the moderate level were metacognitive developing and affective developing strategies, reading and writing skill activating strategies, and culture learning strategies. Finally, the only strategies found to be used at the low level was radio listening strategies.

Question 3: Does the use of English proficiency maintaining strategies correlate with one another?

Although it was found that some strategies were found at high level of intensity, while others are at moderate level and one at low level as reported in the earlier section, analyses of the interrelationship of the use of these strategy categories revealed that most of them were correlated with one another significantly. Table 2 shows that out of 36 correlation coefficients, $81 \%$ show significant correlation at .000 level, $11 \%$ significant at .01 level, and $8 \%$ insignificant. Among coefficients significant at .000 level the highest was between language focusing strategies (factor 1) and text analyzing strategies (factor 8) $(\mathrm{r}=.717, p<.000)$ and the lowest was between language resource utilizing strategies (factor 4) and cognitive processing strategies (factor 5) $(\mathrm{r}=.366, p<.000)$. Moreover, among the four coefficients significant at .01 level the highest was between culture learning strategies (factor 6) dan radio listening strategies (factor 9) ( $\mathrm{r}=.354$, $p<.001)$ and the lowest was between social communicating strategies (factor 7 ) and radio listening strategies (factor 9) ( $\mathrm{r}=.272, p<.008)$. Meanwhile, the insignificant correlations were found between radio listening strategies (factor 9) and language focusing strategies (factor 1) $(\mathrm{r}=.160, p<.124)$, and cognitive processing strategies (factor 5) $(\mathrm{r}=.121, p<.249)$, and text analyzing strategies (factor 8$)(\mathrm{r}=.185, p<.075)$.

Question 4: Do teachers of English with different proficiency levels use maintaining strategies at different intensity?

As described earlier, the subjects were classified into three groups depending on the mean of standard devision of their TOEFL scores and. The scores indicated a mean 426 and a standard deviation 44. The groupings were that those having TOEFL scores higher than a half of standard deviation above the mean were considered upper group ( $\mathrm{n}=26)$, those having TOEFL scores between a half of standard deviation below the mean and a half of standard deviaition above the mean are considered moderate $(\mathrm{n}=38)$, and those having TOEFL scores less than a half of standard deviaition below the mean are considered low group $(\mathrm{n}=29)$. 
When an analysis of variance (ANOVA) was performed to see the effect of proficiency level on the use of each of the nine strategy categories, the study found that none of the F-value was significant. Table 3 indicates that when the use of the nine categories of strategies was compared among teachers with upper, moderate, and lower proficiency, three F-values were found to be more than 1.00 and the other six were lower than 1.00 . However, none was found to be significant with the highest $\mathrm{F}$-value being $2.526(p<.086)$ for strategy 5 , cognitive processing strategies, and the lowest being $.053(p<.948)$ for strategy 9 , radio listening strategies.

\section{Discussion}

The discussion explores the position of the present findings relative to findings of previous studies as well as the possible implications. As far as maintaining strategy classification is concerned, the factor analysis employed in the present study revealed the presence of nine factors, which together explain $63.84 \%$ cummulative variance of English maintaining strategies. This finding suggests that almost twothird of the total maintaining strategy use is assessed in this study. Since there was no other study deals with assessing variances of maintaining strategies using a questionnaire, it is quite difficult to judge whether this proportion of variance is high enough. However, compared with studies in a similar area, i.e. learning strategies, as reviewed by Oxford and BurryStock (1995), this proportion of variance explained in the present study is high. They mentioned that the total variances of learning strategy explained in studies using Strategy Inventory of Language Learning (Oxford, 1990) were $51.6 \%$ in Puerto Rico, $51.9 \%$ in Taiwan, $43.7 \%$ in the People's Republic of China, 53.3\% in Japan, 44.4\% in Egypt, and 51.9 in US. Moreover, when the same instrument was used in Indonesia, the explained total variance of learning strategies was 56.8\% (Mistar, 2006).

Out of the nine underlying factors of English maintaining strategies, the most improtant factor is language focusing strategies, which by itself explains $34.47 \%$ of the total variance. This suggests that to maintain their English proficiency, the teachers focus on forms more than on meanings of the language. Therefore, such strategies as trying to understand text structure when reading, paying attention to the correctness of pronunciation when talking, paying attention to grammar both in speaking and writing, and analyzing grammatical mistakes in writing are prevalent among teachers. This is quite understandable since the teachers are teaching English in a foreign language context, where grade orientation is more common than communicative competence development despite the curriculum's formal objective to develop students' communicative competence. Nyikos and Oxford (1993) asserts that learners in communicative competence oriented contexts prefer strategies that involve active use of the target language, while learners in grade oriented contexts exhibit more strategies that deal with formal, rule-related processing strategies. This tendency may also be reflected in the teachers' strategies in maintaining their English proficiency so that they tend to use form-focused strategies more than meaning-focused strategies.

Metacognitive and affective developing strategies are also on top priority of use among teachers of English in Indonesia context as this strategy category accounts for $6.41 \%$ maintaining strategy variance. This implies that the teachers are aware of the importance of strategies to maintain their English proficiency. Therefore, they intentionally make up schedules to practice English and try to be consistent in implementing the schedule. Then, they monitor and evaluate their English proficiency over times to make sure that they maintain their English proficiency. In this regard, refering to the context of learning Stern (1975) mentions that good language learners are critical of the progress they make in learning a new language. Moreover, the teachers seem to have employed strategies for controlling their emotion and feeling properly. As such they are good speakers of English as they are not inhibited to practice English. Rubin (1975) says that good language learners are not inhibited.

Meanwhile, strategies of listening to radio programs are not common anymore as it explains only $2.24 \%$ variance and this strategy category is used at low level of intensity. This is perhaps due to advancement in other communication devices, such as internet, television, VCDs, and DVDs. Therefore, teachers seldom listen to programs in VOA, BBC, or ABC; instead, they use songs, internet, commands in computer, TV programs, VCDs, and DVDs, which all belong to language resource utilizing strategies, to maintain their English. The latter group of strategies were found to be used at the high level of intensity.

Maintaining English proficiency through learning the culture of the native speakers of English is also not very common among teachers as the use of this strategy category was ranked eight. Again, this finding seems to have something to do with the context of English teaching in Indonesia as a foreign language, instead of a second language. Learners of English in a foreign language context 
tend to be instrumentally motivated, while those in a second language context tend to be integratively oriented. Since the teachers maintain and develop their English proficiency for the sake of their teaching profesionalism, rather than for being parts of the culture of the native speakers of English, then culture learning is not much employed. In the context of learning strategies, Oxford (1990) says that learners of a new language for inter-personal communicative purposes learn differently from those learning simply for a graduation requirement. Based on this assertion, it may be said that teachers of English in a community where English serves as a means of daily communication will employ different maintaining strategies from those teaching in a community where English is taught as a school subject only. One of the differences may be in the use of culture learning strategies.

The present study also found that the use of most of the nine strategy categories was intercorrelated, suggesting a change in the intensity of use of a strategy tends to be followed by a similar change in the use of the other strategies. The strongest correlation is between form focusing strategies (strategy 1) and text analyzing strategies (strategy 8). This is logical as in fact the two types of strategies deal with utilizing language forms. The former deals with the use of language forms in speaking and writing, while the latter with the use of language forms in reading. The second strongest correlation is between reading and writing activating strategies (strategy 3) and language resource utilizing strategies (strategy 4). A closer inspection of the maintaining strategy items of the two types of strategies reveals that the former strategy concerns with maintenance of written skills, while the latter with maintenance of spoken skills. This implies that maintaining a certain skill tends to be followed by maintaining the other three language skills. Conversely, when one experience a decline of proficiency of a skill, a similar decline in the proficiency of the other skills will take place.

The only insignificant correlations were between radio listening strategies (strategy 9) on one hand and language focusing strategies (strategy 1), cognitive processing strategies (strategy 5), and text analyzing strategies (strategy 8) on the other hand. This finding may be explained from the characteristics of the strategies concerned. While radio listening is an extensive skill development activity done to get accustomed to English voices, the other three types of strategies are about intensive skill development activities done to improve comprehension. This different characteristics of the strategies may affect the insignificant correlation among them.

Finally, the present study also found no effect of proficiency level on the use of maintaining strategies. This implies that teachers with different levels of proficiency reported using the same types of maintaining strategies and at the same intensity of use too. Vann and Abraham (1990) found a similar finding when they compared the use of strategies by successfull and unsuccessful learners. Their conclusion says that the unsuccessfull learners used many of the same strategies as the successfull learners. However, Huda's (1999) finding reported that highly proficient learners use learning strategies at different intensity from poorly proficient learners. Thus, more evidence is required on this matter before we arrive at a conclusive theory on the role of proficiency attainment on maintaining strategies.

\section{Conclusion}

To be in line with the research problems, four points of conclusion are presented here. First, there are nine categories of maintaining strategies obtained in the present study. These include (1) language focusing strategies, (2) metacognitive and affective developing strategies, (3) reading and writing activating strategies, (4) language resource utilizing strategies, (5) cognitive processing strategies, (6) culture learning strategies, (7) social communicating strategies, (8) text analyzing strategies, and (9) radio listening strategies. Next, the overall use of these strategies is at a high level of intensity with language focusing strategies being the most intensively used and radio listening strategies being the least. However, the use of these nine strategy categories are found to be inter-correlated. Finally, teachers with different level of English proficiency as measured by a TOEFL test do not exhibit different use of maintaining strategies.

The phenomenon of language loss or language attrition has been quite common among learners of a foreign language, including English in Indonesia, upon the termitation of the formal learning period. To minimize it, they have employ certain strategies to maintain their foreign proficiency. The present study has demonstrated the presence of nine strategy categories that teachers of English in Indonesia use to maintain their English proficiency. Thus, these strategies should be employed effectively in order that they will be able to maintain their English proficiency. However, since this study deals with only teachers of English in East Java, a wider sample 
need to be pursued to come to a more convincing classification of strategies. Moreover, personal factors that may lead to the effectiveness of certain strategies need to be further studied as certain strategies may be effective for a particular group of teachers, while other strategies are effective for teachers with other personal characteristics. Finally, the effect of proficiency level on maintaining strategy use still also need to be studied further with more theoretically-based classification of proficiency levels.

Table 1. Intensity of Use of Maintaining Strategies

\begin{tabular}{lcclc}
\hline \multicolumn{1}{c}{ Strategy Category } & Mean & s.d. & Intensity of Use & Rank of Use \\
\hline 1. Language Focusing & 4.04 & .671 & High & 1 \\
2. Metacognitive and Affective Developing & 3.39 & .749 & Moderate & 6 \\
3. Reading and Writing Skill Activating & 3.18 & .722 & Moderate & 7 \\
4. Language Resource Utilizing & 3.55 & .738 & High & 4 \\
5. Cognitive Processing & 3.73 & .708 & High & 2 \\
6. Culture Learning & 3.00 & .861 & Moderate & 8 \\
7. Social Communicating & 3.50 & .827 & High & 5 \\
8. Text Analyzing & 3.64 & .765 & High & 3 \\
\end{tabular}

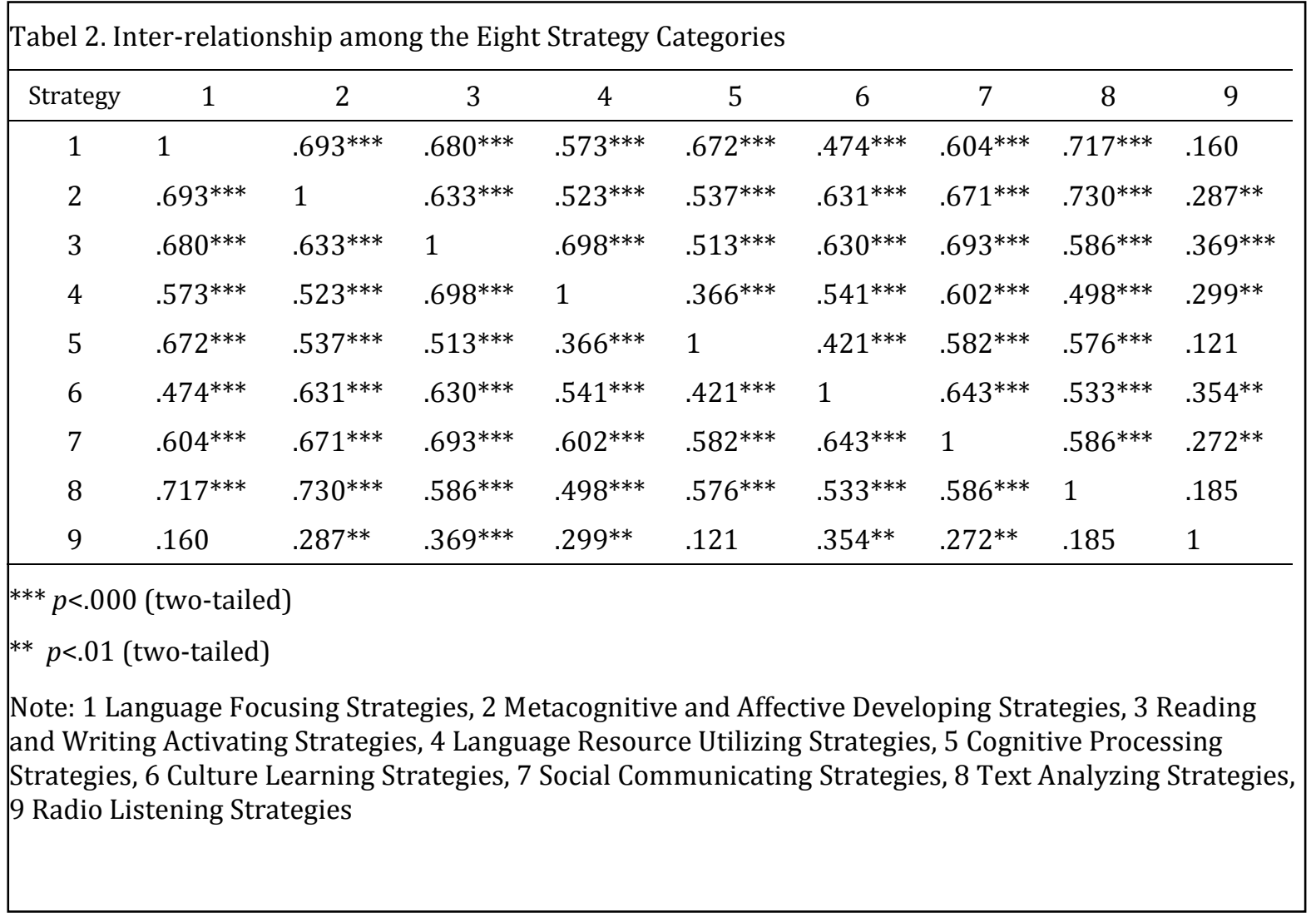




\begin{tabular}{|c|c|c|c|c|c|c|}
\hline Strategy & Sources of Variance & Sum of Squares & $\mathrm{df}$ & Mean Square & $\mathrm{F}$ & Sig. \\
\hline \multirow[t]{3}{*}{1} & Between Group & 207.354 & 2 & 103.677 & 1.023 & .364 \\
\hline & Within Group & 9123.291 & 90 & 101.370 & & \\
\hline & Total & 9330.645 & 92 & & & \\
\hline \multirow[t]{3}{*}{2} & Between Group & 38.005 & 2 & 19.003 & .170 & .844 \\
\hline & Within Group & 10078.920 & 90 & 111.988 & & \\
\hline & Total & 10116.925 & 92 & & & \\
\hline \multirow[t]{3}{*}{3} & Between Group & 132.663 & 2 & 66.331 & .750 & .476 \\
\hline & Within Group & 7964.498 & 90 & 88.494 & & \\
\hline & Total & 8097.161 & 92 & & & \\
\hline \multirow[t]{3}{*}{4} & Between Group & 134.539 & 2 & 67.270 & 1.542 & .220 \\
\hline & Within Group & 3926.192 & 90 & 43.624 & & \\
\hline & Total & 4060.731 & 92 & & & \\
\hline \multirow[t]{3}{*}{5} & Between Group & 120.083 & 2 & 60.042 & 2.526 & .086 \\
\hline & Within Group & 2139.229 & 90 & 23.769 & & \\
\hline & Total & 2259.312 & 92 & & & \\
\hline \multirow[t]{3}{*}{6} & Between Group & 4.667 & 2 & 2.334 & .124 & .884 \\
\hline & Within Group & 1699.333 & 90 & 18.881 & & \\
\hline & Total & 1704.000 & 92 & & & \\
\hline \multirow{3}{*}{7} & Between Group & 19.770 & 2 & 9.885 & .573 & .566 \\
\hline & Within Group & 1551.478 & 90 & 17.239 & & \\
\hline & Total & 1571.247 & 92 & & & \\
\hline \multirow[t]{3}{*}{8} & Between Group & 18.593 & 2 & 9.297 & .993 & .374 \\
\hline & Within Group & 842.439 & 90 & 9.360 & & \\
\hline & Total & 861.032 & 92 & & & \\
\hline \multirow[t]{3}{*}{9} & Between Group & .740 & 2 & .370 & .053 & .948 \\
\hline & Within Group & 627.539 & 90 & 6.973 & & \\
\hline & Total & .628 .280 & 92 & & & \\
\hline
\end{tabular}

\section{REFERENCES}

Bahrick, 1984. Semantic Memory Content in Permasture. 50 Years of Memory for Spanish learned at School. Journal of Experimental Psychology: General, 113, 1-29.

Bialystok, E. \& Fröhlich, M. 1978. Variables of classroom achievement in second language learning. The Modern Language Journal, 62, 327-336.

Berman, R. A., \& Olstain, E. 1989. Feature of First Language Transfer in Second Language Attrition. Applied Liguistics, 4 (3), 222-234.

Clark, J. L. D., \& Jorden, E. H. 1984. A Study of Language Attrition in Former US Students of Japanese and Implication for Design of Curriculum and teaching Material: Final Project Report On line. From ERIC Reproduction Service. Retrieved November 1, 2008.

Cohen, A. 1989. Attrition in the productive lexicon of two Portuguese third language speakers. Studies in Second Language Acquisition, 11 (2), 135-150.

Huda, N. 1999. Language Learning and Teaching: Issues and Trends. Malang. Penerbit IKIP Malang.

Kurashige. 1999. Japanese Returnees' Retention of English Speaking Skills: Changes in Verb Usage over Time. In Hansen (Ed). Second Language Attrition in Japanese Context. New York. Oxford University Press.

Mistar, J. 2002. English learning strategies of Indonesian students across individual differences. Asian Journal of English Language Teaching, 11, 19-44.

Mistar, J. 2006. The effect of learning strategies on perceived english proficiency. Jurnal Pendidikan dan Pengajaran, 4 (1), 2006. 
Nagasawa. 1999. Learning and Losing Japanese as Second Language: A Multiple Case Study of American University Students. In Hansen (Ed). Second Language Attrition in Japanese Context. New York. Oxford University Press.

Nunan, D. 1991. Language Teaching Methodology: A Textbook for Teachers. Norwich: Prentice Hall International (UK) Ltd.

Nyikos, M. \& Oxford, R. 1993. A factor analytic study of language-learning strategy use: interpretations from information-processing theory and social psychology. The Modern Language Journal, 77 (i), 11-22.

Oxford, R. L. 1990. Language learning strategies: what every teacher should know. New York: Newbury House Publishers.

Oxford, R. L. \& Burry-Stock, J. A. 1995. Assessing the use of language learning strategies worldwide with the ESL/EFL version of the strategy inventory for language learning (SILL). System, 23, 1-23.

Oxford, R. L. \& Ehrman, M. E. 1995. Adults' language learning strategies in an intensive foreign language program in the United States. System, 23, 359-386.

Oxford, R., \& Crookall, D. 1988. Learning Strategies. In Gleason, J. B. (Eds). You can Take It with You: Helping Students Maintain Foreign Language Skills beyond the Classroom. New Jersey: Prentice Hall Regent Englewood Cliff.

Pallant, J. F. 2001. SPSS survival manual: a step-step guide to data analysis using SPSS (Version 10). Crows Nest, NSW: Allen \& Unwin.

Park, G. 1997. Language Learning Strategies and English Proficiency in Korean University Students. Foreign Language Annals, 30, 211-221.

Phillips, D. 2001. Longman Complete Course for the TOEFL Test: preparation for the computer and paper tests. New York: Addison-Wesley Longamn, Inc.

Politzer, R. L. \& McGroarty, M. 1985. An exploratory study of learning behaviours and their relationship to gains in linguistic and communicative competence. TESOL Quarterly, 19 (1), 103-123.

Raffaldini, T. 1987. Attrition of Communicative Ability among Formers Year abroad Students of French. Unpublished Doctoral dissertation. Indiana University, Bloomington.

Rubin, J. 1975. What the "good language learner" can teach us. TESOL Quarterly, 9, 41-51.

Rubin, J., \& Thomson, I. 1982. How to be a More Successful Language Learner. Boston: Heinle \& Heinle Publishers, Inc.

Sider, S. R. 2003. Growing up Overseas: Perceptions of Second Language Attrition and Retrieval Amongst Expatriate Children in India.

Stern, H. H. 1975. What can we learn from the good language learner? Canadian Modern Language Review, 31, 304-318.

Tomiyama, M. 1998. The First Stage of Second Language Attrition: A Case Study of a Japanese Returnee. In Hansen L (ed), Second Language Attrition in Japanese Contexts (59-79). New York. Oxford University Press, Inc

Tomiyama, M. 2000. Children second Language Attrtion: A Longitudinal Case Study. Applied Linguistics 21 (3), 304-332.

Tomiyama, M. 2008. Age and Proficiency in L2 Attrition: Data from Two Siblings. Applied Liguistics. 30/2: 253-275

Vann, R. J., \& Abraham, R. G. 1990. Strategies of unsuccessful language learners. TESOL Quaterly, 24, 177198.

Weltens, B., Van Els, T., \& Schils, E. 1989. The Long Term Retention of French by Dutch Students. Studies in Second Language Acquisition. 11 (2), 127-134. 